\title{
Subtle Cognitive Dysfunction in Resolving High Altitude Cerebral Edema Revealed by a Clock Drawing Test
}

\author{
Ian Quigley, MBBS; Ken Zafren, MD \\ From the Western Road Medical Centre, Romford, United Kingdom (Dr Quigley); the Department of Emergency Medicine, Alaska Native Medical \\ Center, Anchorage, AK; the Department of Emergency Medicine, Stanford University Medical Center, Palo Alto, CA; and the Himalayan Rescue \\ Association, Kathmandu, Nepal (Dr Zafren).
}

\begin{abstract}
High altitude cerebral edema (HACE) is a life-threatening condition that can affect people who ascend to altitudes above $2500 \mathrm{~m}$. Altered mental status and the presence of ataxia distinguishes HACE from acute mountain sickness (AMS). We describe a patient with subtle cognitive dysfunction, likely due to HACE that had not fully resolved. When he initially presented, the patient appeared to have normal mental status and was not ataxic. The diagnosis of HACE was missed initially but was made when further history became available. Cognitive dysfunction was then diagnosed based on abnormal performance of a clock drawing test. A formal mental status examination, using a clock drawing test, may be helpful in assessing whether a patient at high altitude with apparently normal mental status and with normal gait has HACE.
\end{abstract}

Key words: altitude sickness, acute mountain sickness, high altitude cerebral edema, high altitude pulmonary edema, hypoxia, clock drawing test

\section{Introduction}

High altitude cerebral edema (HACE) and high altitude pulmonary edema (HAPE) are life-threatening conditions that can affect people who ascend to altitudes above $2500 \mathrm{~m} .{ }^{1}$ Altered mental status and the presence of ataxia distinguishes HACE from acute mountain sickness (AMS). ${ }^{2}$ Patients with AMS or HAPE may be able to continue ascent after treatment, but patients with HACE are advised to descend.

We describe a patient with subtle cognitive dysfunction, likely due to HACE that had not fully resolved. Because the patient had neither altered consciousness nor ataxia when he first presented, the diagnosis was initially missed. The diagnosis of HACE was made only after additional history was obtained from the patient's trekking partner. Continuing cognitive dysfunction was confirmed by the patient's inability to complete a clock drawing test. We share this case because we believe that drawing a clock is a simple test that could be used when assessing patients with high altitude illness.

Corresponding author: Ken Zafren, MD, 10181 Curvi St., Anchorage, AK 99507 (e-mail: kenzafren@gmail.com).

\section{Description of the Case}

A fit 49-year-old man consulted one of the authors (I.Q.) at the Himalayan Rescue Association (HRA) clinic in Manang at $3540 \mathrm{~m}$ on the Annapurna trekking circuit in the Nepal Himalayas. The day before he presented, he reached Thorong Phedi where he spent the night at an altitude of $4550 \mathrm{~m}$. He planned on waking early the next morning to cross the Thorong La (Thorong Pass), 5416 $\mathrm{m}$. On arrival at Thorong Phedi he developed a slight headache. He woke, as planned, at 3:00 AM, with a severe headache. He abandoned the climb and descended to seek help in Manang.

Twelve hours later, at 3:00 PM, the patient reached Manang where he presented, unaccompanied, to the HRA clinic. The headache had resolved but he still felt unwell. There was no history of vomiting, breathlessness, or cough. Past medical history was significant only for well-controlled asthma. The patient was able to converse normally, but was cyanotic and looked ill. Initial oxygen saturation $\left(\mathrm{SpO}_{2}\right.$; Nonin $\mathrm{GO} 29570$ [Nonin Medical, Plymouth, MN]) was $79 \%$ on ambient air with a heart rate of $125 / \mathrm{min}$. There was slight wheezing. No crackles were heard on auscultation of the chest. After 5 minutes rest, $\mathrm{SpO}_{2}$ rose to $88 \%$. With walking, $\mathrm{SpO}_{2}$ 
dropped to $69 \%$. He had normal tandem gait (ability to walk a straight line, heel to toe). Because he had no headache, no ataxia, and was able to talk normally, no further attempt was made to exclude the diagnosis of HACE.

At Manang (3540 m) normal resting $\mathrm{Spo}_{2}$ on ambient air is $88 \%$ to $90 \%$. The patient's $\mathrm{Spo}_{2}$ at rest was within the expected range. We diagnosed resolving AMS. Based on desaturation on exertion, we also diagnosed HAPE. No imaging was available. He was treated with oxygen, oral nifedipine slow release $20 \mathrm{mg}$, and oral sildenafil $50 \mathrm{mg}$. Breathing oxygen at $6 \mathrm{~L} / \mathrm{min}$ by nasal cannula from an oxygen concentrator, his $\mathrm{SpO}_{2}$ rose to $96 \%$.

At 5:00 PM, after 2 hours on oxygen in the clinic, the patient felt much better. His room air $\mathrm{Spo}_{2}$, was in the mid $80 \mathrm{~s}$, similar to his first reading. He paid his bill, counting out the cash without difficulty, and went to his hotel for dinner. At 6:00 PM the patient returned as scheduled for a further 2 hours of oxygen therapy. Because he felt neither better nor worse, there was no formal re-evaluation.

At 8:00 PM, after the patient had received oxygen for 2 more hours, his cousin, who had been his trekking partner, arrived at the clinic to take him back to the hotel. As they left the clinic, the cousin asked the doctor, "Doc, he's been like he's drunk all day. Do you think he's OK?" The cousin went on to describe the patient needing help to put his boots on in the morning. He had then watched the patient stumble awkwardly down the trail, refusing to use his trekking poles. The patient initially presented alone, but now his cousin was describing altered mental status with ataxia that had not been apparent earlier. The patient was asked to return to the clinic for further evaluation.

As before, the patient was talking normally. He still had normal tandem gait. He was able to count backwards from 20 to 1 . When asked to draw a clock face he demonstrated difficulties. His first attempt was a tiny circle, despite having been asked to use the whole sheet of paper. On the second attempt, he started the numbers with 1 in the correct position and managed to reach 11 , where 7 o'clock should have been. He asked whether he should draw a 12- or 24-hour clock. After being told to draw a standard 12-hour clock face, he continued, skipped the number 12 , added the number 13 , and continued to 22 before giving up (Figure 1).

Based on the new information and the abnormal clock drawing test, the patient was diagnosed with HACE that had not completely resolved. He was treated with oral dexamethasone $8 \mathrm{mg}$ and was observed in the clinic overnight, on supplemental oxygen. At 6:45 AM the following morning the patient felt well and said that his

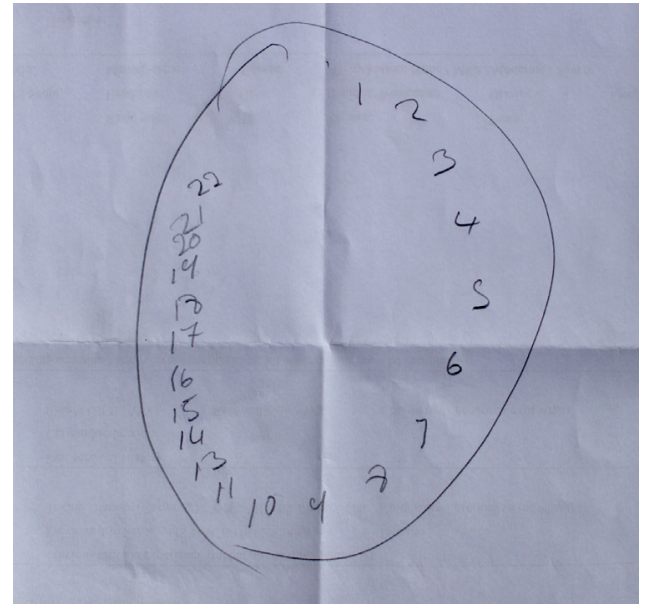

Figure 1. Abnormal clock face drawn by the patient on day 1 .

thinking seemed clearer than it had been the previous day. On ambient air, $\mathrm{Spo}_{2}$ was $90 \%$. He was able to draw a normal clock face, starting with the cardinal numbers 12, 3, 6, and 9 (Figure 2).

Although the patient was keen to continue his trek back up to the Thorong La Pass, it seemed safer to evacuate him by helicopter than to encourage him to continue up or down, on foot or on horseback. He spent 1 night in the hospital in Kathmandu. He was discharged without imaging of the brain. He felt tired and unwell for another day or 2 before feeling completely recovered.

\section{Discussion}

The patient presented feeling generally unwell, after having had a headache. This presentation suggested residual symptoms of AMS. His oxygen saturation was normal for the altitude, but he desaturated on exertion, suggesting a diagnosis of HAPE. Consistent with

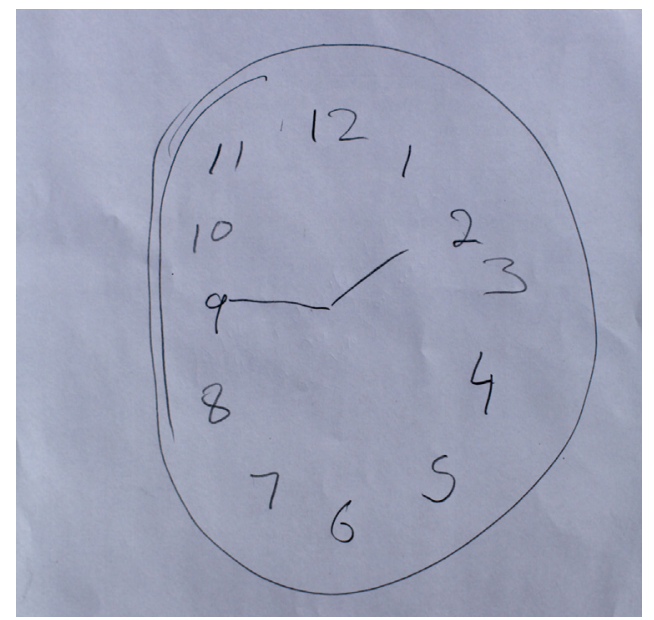

Figure 2. Normal clock face drawn by the patient on day 2 . 
practice previously described at an HRA clinic, he was treated for HAPE with multiple vasodilators. ${ }^{3}$ In response to previously reported cases, the HRA has since issued guidelines for treatment of HAPE that call for use of only a single vasodilator and that recommend against use of multiple vasodilators.

When we first assessed the patient we did not elicit the history of stumbling gait and altered behavior. Informal assessment of mental status during the initial evaluation combined with the observation of normal tandem gait led to the conclusion that the patient did not have HACE. Five hours after the initial presentation, the patient's trekking partner gave new information that strongly suggested a diagnosis of HACE. On further assessment, the patient was able to count backwards but was unable to draw a clock face. Ten hours later, after treatment for HACE, he was able to draw a normal clock face.

The differential diagnosis of headache at high altitude associated with a reversible neurologic deficit included seizure, migraine equivalent, transient ischemic attack, hypoxic encephalopathy, and HACE. The clinical symptoms were atypical for seizure or migraine equivalent. Cerebral hypoxia seemed unlikely because his resting $\mathrm{SpO}_{2}$ on room air was $88 \%$, which is normal for the altitude. The slight increase the next morning to $\mathrm{Spo}_{2}$ $90 \%$ was unlikely to have accounted for the normalization of the results of the clock drawing test. Transient ischemic attack could have presented with ataxia and cognitive dysfunction, but headache was an unlikely symptom. No magnetic resonance imaging was done. We believe that HACE that had not fully resolved was the most likely explanation for the patient's reversible cognitive dysfunction as evidenced by the results of the clock drawing tests.

Clock drawing is usually used as a screening tool for cognitive dysfunction in dementia. Its use has also been described in patients with hepatic encephalopathy and traumatic brain injury. ${ }^{4} \mathrm{We}$ are not aware of previous use of a clock drawing test in patients with HACE. The brain regions used in clock drawing have been studied mainly in patients with dementia. Multiple cortical and subcortical areas and their connections are involved. The abnormal clock drawing test was evidence of cognitive dysfunction that had previously been missed. The patient's abnormal clock drawing indicates spatial planning deficits, perseveration, and conceptual deficits. ${ }^{4}$

This case was a near miss because the initial assessment did not elicit subtle signs of cognitive dysfunction. The patient did not seem confused, but no formal attempt was made initially to assess his mental status. Had the trekking partner not provided additional information, there would have been no further testing of cognitive function.

Patients treated for AMS or HAPE can safely resume ascent soon after recovering. Re-ascent in patients with HACE is not recommended until the patient is completely asymptomatic and is no longer taking dexamethasone. ${ }^{1}$ Because dexamethasone has a long duration of action, re-ascent the following morning would have been ill-advised. Had the patient ascended the morning after being treated for HACE, as he was keen to do, he would have been at risk of redeveloping HACE with potentially fatal consequences. We believe that if a formal cognitive test had been used in the initial assessment, the results would have been abnormal and the diagnosis of HACE would have been considered.

The clock drawing test is easy to administer, even in an austere environment. Although clock drawing has not been studied for the diagnosis of HACE, a formal mental status examination, using a clock drawing test, may be helpful in assessing whether a patient at high altitude with apparently normal mental status and with normal gait has HACE.

\section{Acknowledgments}

We would like to thank the patient for allowing us to present this case, the volunteers and staff at the HRA Manang Clinic (Tracy Quigley, RGN; Carolyn KellySmith, MD; Thaneshwar Bhandari; and Indira Ojha) for their assistance in caring for the patient, and Dr. Buddha Basnyat, Medical Director of the HRA, for his encouragement in publishing this case report. The patient was seen while Dr. Ian Quigley was a volunteer at the HRA Manang Clinic.

\section{References}

1. Luks AM, McIntosh SE, Grissom CK, et al. Wilderness medical society practice guidelines for the prevention and treatment of acute altitude illness: 2014 update. Wilderness Environ Med. 2014;25(4 Suppl):S4-S14.

2. Hackett PH, Roach RC. High altitude cerebral edema. High Alt Med Biol. 2004;5:136-146.

3. Fagenholz PJ, Gutman JA, Murray AF, Harris NS. Treatment of high altitude pulmonary edema at $4240 \mathrm{~m}$ in Nepal. High Alt Med Biol. 2007;8:139-146.

4. Eknoyan D, Hurley RA, Taber KH. The clock drawing task: common errors and functional neuroanatomy. J Neuropsychiatry Clin Neurosci. 2012;24:260-265. 